\title{
Long-Term Evaluation of the Impact of the H1-Receptor Antagonist Cetirizine on the Behavioral, Cognitive, and Psychomotor Development of Very Young Children with Atopic Dermatitis
}

\author{
JIM STEVENSON, DEBORAH CORNAH, PHILIPPE EVRARD, VALERE VANDERHEYDEN, \\ CATHERINE BILLARD, MARTIN BAX, AND ANNE VAN HOUT, ON BEHALF OF THE ETAC \\ STUDY GROUP \\ Department of Psychology, University of Southampton, Southampton, U.K. [J.S., D.C.]; Department of \\ Neuropediatry, Hopital Robert Debré, Paris, France [P.E.]; Universitaire Ziekenhuizen, Gasthuisberg, Leuven, \\ Belgium [V.V.]; Hôpital de Bicêtre, Paris, France [C.B.]; Mac Keith Press, High Holbom House, London, \\ U.K. [M.B.]; Université Catholique de Louvain, Neuropediatry Department, Brussels, Belgium [A.v.H.]
}

\begin{abstract}
The impact of the prolonged use of cetirizine at high dose $(0.25 \mathrm{mg} / \mathrm{kg}$ twice a day over $18 \mathrm{mo})$ on behavior and cognitive ability was examined in a double-blind, randomized, placebocontrolled trial (ETAC-Early Treatment of the Atopic Child) designed to establish whether it was possible to prevent young children (1-2 y old at study entry) with atopic dermatitis from developing asthma. Well-validated and standardized measures of behavior (Behavior Screening Questionnaire) and cognition (McCarthy Scales of Children's Abilities) were used. In addition, the ages of attainment of psychomotor milestones were established. These measures were taken between an average of 32 and 53 mo of age, both during the study treatment with cetirizine or placebo and after the study treatment had been discontinued. The Behavior Screening Questionnaire was completed at least once on approximately 300 children in each group and on approximately 200 children on five occasions. The McCarthy Scales of
\end{abstract}

\section{ABSTRACT}

Children's Abilities were administered to approximately 100 in each group at three different times. There were no significant differences between the cetirizine and placebo groups on either of the behavior and cognition measures or in psychomotor milestones during or after the study treatment. These findings suggest that there are no adverse effects on behavior or learning processes associated with the prolonged use of cetirizine in young children with atopic dermatitis. (Pediatr Res 52: 251-257, 2002)
Abbreviations
ETAC, Early Treatment of the Atopic Child
BSQ, Behavior Screening Questionnaire
MSCA, McCarthy Scales of Children's Abilities
GCI, General Cognitive Index
GMQ, Global Medical Questionnaire

There is evidence that the use of some antihistamines has an effect on behavior and that this is shown most markedly as sedation (1-3). These side effects may have implications for the long-term development of the child. Little is known about the development of histamine receptors with age, and, given that all antihistamines can gain access to the brain (4), it is important to establish whether antihistamines have a deleterious effect on histamine receptor sites and on the cognitive and behavioral systems regulated by histamine (5). There has been

Received December 21, 2000; accepted November 15, 2001.

Correspondence and reprint requests: Jim Stevenson, Ph.D., Centre for Research into Psychological Development, Department of Psychology, University of Southampton, Highfield, Southampton SO17 1BJ, U.K.; e-mail: jsteven@psy.soton.ac.uk

Supported by UCB S.A., Brussels, Belgium.

DOI: 10.1023/01.PDR.0000024060.49308.89 no study on the impact of the long-term administration of antihistamines on children's behavioral development. The present study aimed to fill this gap.

A number of findings that have suggested that firstgeneration antihistamines can interfere with learning. Sedating (diphenhydramine) and nonsedating (loratadine) antihistamines and a placebo have been used with children suffering from seasonal allergic rhinitis (6). It was found that those on placebo and diphenhydramine learned significantly less well than healthy controls. The nonsedating antihistamine only partially counteracted this effect. A subsequent study of young adults with seasonal allergic rhinitis showed that this learning deficit could be avoided by the use of a combination compound of acrivastine and pseudoephedrine (7). The indications from these previous studies made it essential to determine whether 
the prolonged use of any pharmacological treatment with antihistamines had a detrimental effect on learning, cognitive development, and behavior in children with atopic eczema.

The potential value of cetirizine as a prophylactic against the transition from atopic dermatitis to asthma has been reported for the ETAC study (8). This was a parallel group, doubleblind, randomized, and placebo-controlled trial where cetirizine was administered at one to two times the recommended dose in 817 young children (1-2 y of age at inclusion) for a long period $(18 \mathrm{mo})$. The reduction in asthma onset was not significant for the intention-to-treat sample. However, there were very significant reductions in asthma onset for children with elevated IgE for house dust mite and grass pollen. For these subgroups, which constitute $18 \%$ and $11 \%$, respectively, of the children with atopic dermatitis, clinically significant gains are to be had from the prophylactic use of cetirizine. There are concerns that the prolonged use of a pharmacological treatment in small children may create threats to their physical health and cognitive and behavioral development. The ETAC study was a unique opportunity to assess the effect on behavior and cognition of such a treatment.

The overall safety results of the study are reported elsewhere (9). Double-blind, parallel cetirizine or placebo groups showed no clinically relevant differences for neurologic or cardiovascular symptoms, growth, laboratory tests results, or electrocardiograms and no child had prolongation of the $\mathrm{QT}_{\mathrm{c}}$ interval. This article presents an account of the behavioral or cognitive development of children within this trial.

\section{METHODS}

The behavior and psychomotor development evaluation of the ETAC children was co-ordinated by a scientific advisory sub-board consisting of independent clinicians and scientists. The study protocol was given ethical approval at each of the sites in each of the 14 countries involved in ETAC. The children were enrolled into the study between their first and second birthdays, after written informed consent was obtained from their parents or guardians. They had atopic dermatitis and at least one parent or sibling with a history of atopic dermatitis, allergic rhinitis, or asthma. Children with severe developmental or behavior problems, a history of neonatal distress, or sleep apnea (subject or siblings) were not included in the trial [more details on subject selection can be found in Ref. (8)].

Cetirizine $(0.25 \mathrm{mg} / \mathrm{kg}$ body weight $)$ or placebo was administered orally twice daily in the morning and in the evening. At each clinic visit, the appropriate dosage according to the child's weight was evaluated by the investigator. Accuracy of dosing was ensured by the use of a table of correspondence between body weight, dose, and number of drops per intake and by weighing the remaining study samples at the end of the treatment period.

Behavior measures. The children's behavior was assessed using the BSQ (10). The BSQ is a semi-structured screening interview, which provides a series of validated questions addressed to the parents concerning the child's health, behavior, and development in the past $4 \mathrm{wk}$. The BSQ deals with the following 12 aspects of behavior: eating, soiling, sleeping, activity, concentration problems, relationships, dependency, management problems, tantrums, moods, worries, and fears. The interviews were carried out by medical staff at the time of visits to the clinic.

For each aspect of behavior, standardized questions are asked that prompt the parents to provide detailed accounts of the frequency, intensity, and duration of behavior. On the basis of these accounts, a rating was made of the severity with which the behavior is affected using a prespecified set of categories. In 12 areas of behavior, a $0-2$ scoring system is used, where 0 indicates the absence of problems in that area, 1 indicates the behavior is present to a mild degree, and 2 indicates that a behavior problem is definitely present. These items are aggregated to give a total BSQ score with a possible range from 0 to 24 [for details of the scoring see Ref. (11)]. The BSQ can be analyzed either in terms of a mean total BSQ score or by determining the number of individuals that exceed a cutting point of 10 of more, which has been shown to identify a group of 3-y-old children at risk for long-term behavioral difficulties (12). All the investigators were specifically trained before using this measure.

Ability levels. The children's cognitive development was assessed using the MSCA (13). This test comprises 18 separate tests that assess the child's mental abilities. The tests are grouped into five different scales, covering the verbal (V), perceptual performance $(\mathrm{P})$, quantitative $(\mathrm{Q})$, memory, and motor aspects. A composite scale is derived - the GCI, which is the aggregate of $\mathrm{V}, \mathrm{P}$, and $\mathrm{Q}$. The child's raw score is converted to a scaled score according to age (mean $=100, \mathrm{SD}$ $=16$ ) and these scaled scores for the GCI will be reported here. The MSCA was given by selected and specially trained psychologists and all the individual data from the tests were centrally reviewed by a single reviewer, experienced in this methodology to enhance the homogeneity of the measurement. The test is applicable to children from 2.5 to $8.5 \mathrm{y}$ old and is translated and validated in English (13), French (14), and Dutch (15). The MSCA test has been widely used for mental and motor development assessment in children of preschool age. For example, it has been found to be sensitive in detecting the beneficial effects of breast-feeding for preterm infants (16), the difference in cognitive development in children identified as high and low risk for neurodevelopmental problems in infancy (17), and the adverse effects of maternal phenylketonuria on children's cognitive development (18).

Developmental milestones. A GMQ was developed by UCB to assess aspects of the early medical history and development of the children in the trial. The data reported here relate to children's psychomotor development. Based on parental report, the ages in months were determined at which the child attained gross motor abilities (sits alone, crawls, stands alone, walks alone, climbs stairs with assistance, climbs stairs without assistance and runs), fine motor control (pincer grip, pencil grip, matches cubes, and hand preference), and speech/ language milestones (first five words, names many objects, and uses short sentences).

Timing of assessment. On entry to the ETAC protocol, the children had a mean age of 17 mo. They were seen over a period of $18 \mathrm{mo}$, during which they took the study treatment 
(visits 1-8) and then for three subsequent visits after the study medication had been stopped (visits 9-11, 24-36 mo after inclusion). The number of children receiving each assessment and their ages are presented in Table 1.

The BSQ was obtained after 15 and 18 mo (visits 7 and 8) of the treatment period and during the post-treatment follow-up period after 6,12, and 18 mo after discontinuation of the treatment (visits 9-11). The number of children providing data on the BSQ at visit 7 was reduced as a consequence of a delay in initiating BSQ measures in some centers. The MSCA were administered on visits 8,9 , and 11 , but were only administered in centers with 10 or more patients in France, The Netherlands, and the United Kingdom, as the test has been translated and validated in those three languages. The GMQ was first administered on visit 7 and repeated on visits $8-11$.

Statistical methods. All the data were analyzed using the SAS Version 6.12 (SAS, Cary, NC, U.S.A.). For all three measures (BSQ, MSCA, and GMQ), the population used in the analysis consisted of all children included in the intention to treat (ITT) population (i.e. all randomized subjects who received at least one dose of study treatment and for whom follow-up information was available) and for whom data for the corresponding test were available.

The power of the study was quite adequate. The numbers in each group were approximately 200 for the five BSQ analyses (visits 7-11) and about 300 for at least one assessment. The sample size was similar for the milestones measured on the GMQ. With two samples of that size, there was $80 \%$ power to detect an effect size of 0.25 (the difference in means divided by the pooled SD) with two-tailed $\alpha=0.05$ (19). This effect size $(0.25)$ would be equivalent to a difference in means on the BSQ of 1.5 and, for example, for the GMQ milestone of "run" a difference of $1.2 \mathrm{mo}$. Both these differences are smaller than that which would be considered as clinically significant (20). For the MSCA, the numbers were approximately 100 in each group. With two samples of that size, there was $80 \%$ power to detect an effect size of 0.40 with two-tailed $\alpha=0.05$. This effect size would be equivalent to 6 points on the GCI. For the MSCA, too, an effect size of 0.40 or more would be considered as clinically significant (20). There was more than sufficient power in the study to detect any effects of prolonged use of cetirizine that were clinically significant.

The BSQ. The total BSQ scores were analyzed using a repeated measures ANOVA during the treatment period (visits 7 and 8) and after discontinuation of the study medication (visits 9-11). Treatment group and visit were included in the model as factors. A possible interaction effect between treat- ment and visit was hypothesized. The treatment effect was estimated by calculating the difference between the least squares means of the placebo group and the cetirizine group and its $95 \%$ confidence interval. The 12 aspects of problem behavior were analyzed by determining the number of children with problem behavior for each aspect. At each visit, the relative risk for having an abnormal value for the BSQ $(>10)$ in the cetirizine-treated group was compared with the placebotreated group, and these are presented together with the corresponding confidence interval.

The MSCA. The GCI was analyzed using a repeatedmeasures ANOVA for visits 8, 9, and 11. Visits 7 and 10 had too few observations to be included in this analysis. The treatment effect was estimated by calculating the difference between the least squares mean of the placebo group and the cetirizine group and its $95 \%$ confidence interval. Treatment, visit, and language were included in the model as factors. Possible interaction effects involving treatment were tested.

\section{RESULTS}

The baseline characteristics of the children having a BSQ or a MSCA assessment are similar to those of the whole ETAC population for the main baseline and demographic characteristics. They were on average $17 \mathrm{mo}$ (range 10.6-28.6 mo) of age on entry to the trial. Boys constituted $62 \%$ and girls $38 \%$ of the sample. The mean weight at baseline was $11 \mathrm{~kg}$. The mean index of eczema severity was 25 . This average figure is considered to be on the borderline between mild and moderate/ severe atopic dermatitis. The placebo and control groups did not differ on these measures, and neither were there significant differences between those taking part in the present study of behavior and cognition and the ETAC sample as a whole. The sample used in the analysis of psychomotor and behavioral development can be considered as representative of the whole ETAC population.

Behavior problems. The mean scores on the BSQ during the treatment period (visits 7 and 8) and during the post-treatment follow-up (visits 9-11) are presented in Table 2. The mean total BSQ score was comparable for both treatment groups. At the visits under treatment (visit 7 and 8) and at visit 9, the BSQ was lower in the cetirizine group compared with the placebo group. Afterward (visits 10 and 11), the total BSQ score was slightly higher in the cetirizine compared with the placebo group. The overall estimated treatment effect (difference in overall means for cetirizine and placebo) was $0.12(95 \%$ confidence interval $=-0.34,0.58$ ). This treatment effect was

Table 1. Numbers and ages (in months) of children on whom BSQ, MSCA, and GMQ data were obtained

\begin{tabular}{|c|c|c|c|c|c|c|c|}
\hline \multirow[b]{2}{*}{ Visit } & \multirow{2}{*}{$\begin{array}{l}\text { Mean age } \\
\text { in months }\end{array}$} & \multicolumn{3}{|c|}{ Placebo } & \multicolumn{3}{|c|}{ Cetirizine } \\
\hline & & BSQ $(n)$ & $\operatorname{MSCA}(n)$ & GMQ $(n)$ & BSQ $(n)$ & $\operatorname{MSCA}(n)$ & GMQ $(n)$ \\
\hline Overall & - & 294 & 112 & 285 & 303 & 117 & 297 \\
\hline $8^{*}$ & 35 & 170 & 83 & - & 180 & 92 & - \\
\hline $9 \dagger$ & 41 & 254 & 107 & - & 255 & 105 & - \\
\hline $10 \dagger$ & 47 & 237 & - & - & 236 & - & - \\
\hline
\end{tabular}

* During treatment; $\dagger$ after treatment. 
not statistically significant. Table 2 shows that there was an effect of visit such that the BSQ score declined with age, indicating that older children had fewer problems. To summarize, the results in Table 2 reveal no relevant effect of cetirizine on children's behavior or a rebound effect after terminating the treatment period.

The effects of treatment on behavior can also be examined by the number of children gaining clinically significant scores (i.e. above 10) by treatment and by visit. These data are presented in Table 3. The relative risks and their confidence interval assess the risk of having an elevated total BSQ score under cetirizine treatment compared with placebo. A pattern of lower behavior scores with age was seen, but at no time point was the relative risk of a BSQ score $>10$ significant for cetirizine compared with placebo.

Although there were no significant effects of cetirizine on total BSQ score, it was of interest to know whether specific aspects of behavior indicated any differences. There were more marked cases of problems with concentration, attention, and sleep in the placebo group at visit 7. As expected, fewer marked cases were observed for the problem of soiling as the study progressed and the children grew older. Marked tantrums were more common in the cetirizine group $(7.6 \%$ at visit 7 , $6.1 \%$ at visit $8,3.9 \%$ at visit $9,4.2 \%$ at visit $10,2.5 \%$ at visit $11)$ compared with placebo $(7.2 \%$ at visit $7,4.7 \%$ at visit 8 , $1.6 \%$ at visit $9,2.5 \%$ at visit $10,0.4 \%$ at visit 11$)$. No relevant differences between the treatment groups were found for aspects of relationships, management, hyperactivity, fears, worries, moods, and eating. The last of these might have been expected to be effected inasmuch as appetite increase is sometimes reported with other antihistamines (21). In conclusion, the cetirizine and the placebo group were very similar in the rates of specific problem behaviors and there was no evidence of a significant impact of prolonged cetirizine treatment on problematic behaviors.

Cognitive ability. The normal range of the GCI is situated from 84 to 116 . Values above 116 are considered as exceptional and values below 84 are considered to place the child at risk for educational difficulties. The mean scores on the GCI by treatment group at visits 8,9 , and 11 for all languages together are presented in Table 4. The mean GCI in the cetirizine and the placebo groups were very similar.

The estimated effect of treatment on the GCI (overall difference in cetirizine and placebo means) was $-0.81(95 \%$ confidence interval $=-4.06,2.43$ ). This treatment effect was not statistically significant. There was a significant effect of visit such that the GCI score increased with time; however, this was not a linear average trend and the increase followed a different pattern over time in the different language groups. The effect of visit did not interact with treatment, but there was a borderline significant interaction between treatment and language group $(p<0.095)$. This means that the treatment effect remained constant over time, but there were slight differences in the size of the treatment effect between the French-, English-, and Dutch-speaking children. However, the treatment effect was consistently nonsignificant in each of the language groups (English, French, and Dutch).

A more-detailed description of the GCI shows that there are some slight differences between the individual language groups. The English language group has at each visit a higher GCI under cetirizine compared with placebo, whereas the GCI

Table 2. Total BSQ scores for placebo and cetirizine groups by visit

\begin{tabular}{|c|c|c|c|c|c|c|}
\hline \multirow[b]{2}{*}{ Visit } & \multicolumn{3}{|c|}{ Placebo } & \multicolumn{3}{|c|}{ Cetirizine } \\
\hline & $n$ & Mean & SD & $n$ & Mean & SD \\
\hline $7 *$ & 97 & 7.1 & 3.53 & 92 & 6.4 & 3.18 \\
\hline $9 \dagger$ & 254 & 5.9 & 3.32 & 255 & 5.7 & 3.16 \\
\hline $10 \dagger$ & 237 & 5.2 & 3.14 & 236 & 5.4 & 3.49 \\
\hline $11 \dagger$ & 232 & 4.6 & 3.10 & 237 & 4.7 & 3.49 \\
\hline
\end{tabular}

* During treatment; $\uparrow$ after treatment.

\begin{tabular}{lcrc}
\hline \multicolumn{1}{c}{ Effect } & $d f$ & $F$ & $p$ \\
\hline Treatment & 1.581 & 1.03 & NS \\
Visit & 1.509 & 144.23 & $<.0002$ \\
Treatment $\times$ visit & 1.509 & 1.40 & NS \\
\hline
\end{tabular}

Table 3. Percentage with BSQ scores above 10 for placebo and cetirizine groups by visit

\begin{tabular}{|c|c|c|c|c|c|c|}
\hline \multirow[b]{2}{*}{ Visit } & \multicolumn{2}{|c|}{ Placebo } & \multicolumn{2}{|c|}{ Cetirizine } & \multirow{2}{*}{$\begin{array}{c}\text { Relative risk } \\
\text { (RR) }\end{array}$} & \multirow[b]{2}{*}{$95 \% \mathrm{CI}$ for $\mathrm{RP}$} \\
\hline & $n$ & $\%$ & $n$ & $\%$ & & \\
\hline $7^{*}$ & $25 / 97$ & 25.8 & $16 / 92$ & 17.4 & 0.67 & $0.39-1.18$ \\
\hline $9 \dagger$ & $38 / 254$ & 15.0 & $28 / 255$ & 11.0 & 0.73 & $0.47-1.16$ \\
\hline $10 \dagger$ & $20 / 237$ & 8.4 & $26 / 236$ & 11.0 & 1.31 & $0.75-2.27$ \\
\hline $11 \dagger$ & $17 / 232$ & 7.3 & $19 / 237$ & 8.0 & 1.09 & $0.58-2.05$ \\
\hline
\end{tabular}

* During treatment; $\uparrow$ after treatment. CI, confidence interval. 
Table 4. GCI scores for placebo and cetirizine groups by visit



is lower in the cetirizine compared with the placebo group for the Dutch and the French language.

Developmental milestones. The mean age at which children in the cetirizine and placebo groups attained milestones in gross motor, fine motor, and speech/language development are shown in Table 5. The results are very similar for the two groups. There was no tendency for one group to be delayed relative to the other and in no case was there more than a 1-mo difference in the mean ages. For none of the milestones are the mean ages significantly different. The findings from the GMQ give no indication of any adverse effect on overall development of prolonged treatment with cetirizine.

\section{DISCUSSION}

This study was designed to establish whether the use of cetirizine over an 18-mo period would have adverse effects on mental and behavioral development while the antihistamine was being taken and over the subsequent $18 \mathrm{mo}$ as well. There are a number of possible mechanisms whereby prolonged use of antihistamines might have been expected to have an adverse effect on behavior and cognitive development. First, the pharmacological effects of the drug might have a concurrent effect on behavior, and this effect might become compounded by prolonged exposure to the drug. Second, a child might become upset by the repeated administration of the study medication. This might have a negative impact on feeding behaviors or a wider effect on behavior (22). Third, the parents' responses to a prolonged trial might heighten their concern over the child's development that would then impact on parenting behavior and on aspects of expressed emotion (23), perhaps, most particularly, overprotection or emotional overinvolvement. It is known that such parental responses can impact on a child's behavior (24).

Despite this complex set of possible mechanisms whereby the prophylactic use of cetirizine might effect children's development, there was no evidence in the results of the present study to indicate negative effects of prolonged administration of cetirizine. No influence on the children's overall behavioral and psychomotor development could be demonstrated after an 18-mo treatment with a high dose of cetirizine in young children.

It is possible that there are other mechanisms operating that have yet to show an effect by age $4.5 \mathrm{y}$. These include possible effects on neurotransmitter sites, which are still developing in

Table 5. Ages (in months) for attaining gross and fine motor and speech/language milestones for placebo and cetirizine groups

\begin{tabular}{|c|c|c|c|c|c|c|}
\hline \multirow[b]{2}{*}{ Milestone } & \multicolumn{3}{|c|}{ Placebo } & \multicolumn{3}{|c|}{ Cetirizine } \\
\hline & $n$ & Mean & SD & $n$ & Mean & $\mathrm{SD}$ \\
\hline \multicolumn{7}{|l|}{ Gross motor } \\
\hline Crawl & 186 & 8.5 & 1.63 & 185 & 8.7 & 1.71 \\
\hline Stand & 220 & 10.6 & 2.13 & 228 & 10.6 & 2.10 \\
\hline Walk & 250 & 12.8 & 2.12 & 263 & 12.9 & 2.14 \\
\hline Climb stairs with assistance & 173 & 14.5 & 4.76 & 193 & 14.6 & 3.78 \\
\hline Run & 203 & 18.0 & 4.80 & 203 & 18.0 & 4.84 \\
\hline \multicolumn{7}{|l|}{ Fine motor } \\
\hline Pincer grip & 136 & 10.3 & 5.46 & 141 & 10.3 & 4.62 \\
\hline Pencil grip & 165 & 20.4 & 9.74 & 152 & 20.9 & 9.53 \\
\hline Match cubes & 183 & 17.9 & 5.38 & 172 & 17.9 & 5.81 \\
\hline Hand preference & 179 & 20.7 & 10.10 & 187 & 19.8 & 9.49 \\
\hline \multicolumn{7}{|l|}{ Speech/language } \\
\hline
\end{tabular}


children. These may require longer-term follow-up to detect. However, it should be noted again that this study was not able to detect adverse effects on behavior and cognition up to $18 \mathrm{mo}$ after the end of treatment.

There are two main reasons why a true difference between the cetirizine and placebo groups may not have been detected (type II error). The first is that the measures of cognition, behavior, and development were not sufficiently sensitive to detect the effect. The second is that the study lacked statistical power.

The sensitivity of the MSCA test has been demonstrated previously. This test has been used to detect the adverse effects of phenytoin in utero on neurobehavioral development (25). It has also been found in a number of studies to be able to detect the effects of low-level lead exposure on cognitive development in children under the age of 4 y $(26-28)$ and also the effects of prenatal exposure to a wider variety of heavy metals (29). Therefore, although there have been no previous studies indicating an adverse effect of antihistamine on the GCI from the MSCA, the test has been shown to be sensitive to the effects of drugs and environmental toxins.

The BSQ measure has been used in a large number of epidemiologic studies and has been shown to be a sensitive indicator of the impact of a variety of risk factors on preschool children's behavior (30). It has been used in other studies of the pharmacological impact on preschool children's behavior (31). In studies of toxins, it has been shown to be sensitive, for example, in relation to in utero exposure to alcohol (32). It can be concluded that the absence of any adverse effect on behavior, cognition, and development of the prolonged administration of cetirizine for children with atopic dermatitis is not due to the use of outcome measures of insufficient sensitivity. As discussed above, the study had $80 \%$ power to detect any clinically significant effects, with a standardized effect size of at least 0.4 .

This study of the behavioral and cognitive side effects of the prolonged prophylactic use of cetirizine with young children had a number of potential weaknesses. The behavioral measurement did not start until the children were $32 \mathrm{mo}$ of age. It would have been preferable to study behavior from the age of entry into the trial at 17 mo of age. Similarly, the assessment of mental development was delayed until the children were $3 \mathrm{y}$ of age. The follow-up period covered in this report is for a period of $18 \mathrm{mo}$ after the trial had finished. As discussed above, it is possible but unlikely that longer-term effects may be present, even in the absence of discernible adverse effects. Ideally, the children's behavior and learning would have been monitored in the context of preschool educational settings as well as by the parents and in the clinic setting.

In contrast to the first-generation antihistamines, cetirizine has lower CNS penetration (33) and, consequently, less effect on CNS functioning (34). Histamine is a neurotransmitter that has a wide regulatory role in brain activity, and diverse adverse effects on behavior and cognition would be expected from any down-regulation of histamine activity (5). The residual CNS penetration for cetirizine is insufficient to produce detectable effects on behavior and cognition in the present study. Given the efficacy of cetirizine to reduce asthma onset, at least for children with atopic dermatitis who are sensitized to grass pollen or house dust mite, it is possible that cetirizine has a beneficial effect on behavior by reducing asthma symptoms and any secondary effects this might have on behavior.

The prolonged use of cetirizine $(0.25 \mathrm{mg} / \mathrm{kg}$ body weight twice per day) in children with atopic dermatitis as a preventive measure against the transition to asthma has not been shown to produce any adverse effects on cognition, development, or behavior either while the drug was being taken or after its administration had been discontinued.

Acknowledgments. The ETAC Study Group. The Writing Committee: J.O. Warner (Southampton, U.K.) and the other members of the ETAC Scientific Advisory Board: L. Businco (Rome, Italy), G. Casimir (Brussels, Belgium), T.L. Diepgen (Heidelberg, Germany), M. Kjellman (Linköping, Sweden), K. Knol (Groningen, The Netherlands), J.L. Menardo (Montpellier, France), C. Naspitz (Sao Paulo, Brazil), F.E.R. Simons (Winnipeg, Canada), U. Wahn (Berlin, Germany). For the UCB ETAC Team (Brussels, Belgium): C. Agboton, M. de Longueville, M.C. de Patoul, M. Vandepaer. Investigators and Co-Investigators: M. Albertini, T. Bourrier (Nice, France), C.P. Bauer, R. Franz (Munich, Germany), G. Bellon, M. Prudon (Lyon, France), E. Bodart (Yvoir, Belgium), A. Boner, P. Fortunati (Verona, Italy), J. Botey, A.M. Marin (Barcelona, Spain), G. Cavagni, M. Gardenghi (Brescia, Italy), R. Clifford, H. Griffith, G. Tutt (Dorchester, U.K.), J.P. Darras (Béziers, France), F.M. de Benedictis, P. Pazzelli (Perugia, Italy), L.E. De Raeve, A. Kempinaire (Brussels, Belgium), B. Deruyter (Brussels, Belgium), G. Dutau, F. Rancé, M. Dufourg (Toulouse, France), I. Eichler, R. Rath (Vienna, Austria), J.L. Fauquert, A. Piollet, D. Masclaux (Beaumont, France), A. Fiocchi, M. Travaini (Milan, Italy), R. Fölster-Holst, I. Lange (Kiel, Germany), K.D. Foote, R. Cottam, P. Gandy (Winchester, U.K.), R.W. Griffioen, J.H. Sillevis Smitt, J.C. Van Nierop, M. de Lange, J. Aalbers (Amsterdam, The Netherlands), A. Grimfeld, F. Sahraoui, F. Lefèvre (Paris, France), M.H. Guillet, G. Guillet (Brest, France),D. Gustafsson, L. Ekholm (Örebro, Sweden), D. Hamel-Teillac, Y. de Prost (Paris, France), I. Huttegger (Salzburg, Austria), A. Labbé (Clermont-Ferrand, France), M.T. Laso-Borrego, A. Mesa-Palomino (Madrid, Spain), J. Leclercq-Foucart, V. Heinrich (Liège, Belgium), R. Lever, G. Ward (Glasgow, U.K.), W. Lipschutz, B. Lipschutz (Antwerp, Belgium), G. Lorette (Tours, France), C. Marguet (Rouen, France), M. Masi, F. Specchia (Bologna, Italy), P. Meglio, P. Lucenti, M.T. Moretti (Rome, Italy), C. Möller, G. Forsberg (Umeå, Sweden), F. Muñoz-Lopez, M.T. GinerMuñoz (Barcelona, Spain), A.P. Oranje, A. Wolkerstorfer, H.J. Neijens (Rotterdam, The Netherlands), A.M. OudesluysMurphy, R.N. Sukhai (Rotterdam, The Netherlands), K.P. Paul, R. Nickel (Berlin, Germany), M. Petrus, M. Rhabbour, A. Trapes (Tarbes, France), I. Pollock, M. Baird-Snell (Enfield, U.K.), A. Prehn, R. Seger (Zürich, Switzerland), S. Ridout, S. Matthews, F.C. Kennedy, D. Pearson (Newport, U.K.), J. Ring, D. Abeck (Munich, Germany), J. Robert, E. Maumet-Verrot (Lyon, France), U. Schauer, S. Köhler (Bochum, Germany), R. Seligmann, C. de Beaufort (Luxembourg, Luxembourg), V. Spièak (Prague, Czech Republic), J.F. Stalder, F. Phéline, M.F. 
Baudrand (Nantes, France), J. Stevenson (Southampton, U.K.), I.L. Strannegård, M. Borres (Göteborg, Sweden), A. Taïeb, C. Labrèze, D. Chevalier (Bordeaux, France), J.P. Van Biervliet (Brussels, Belgium), J.K. Van der Woude (Enschede, The Netherlands), V. Vanderheyden (Leuven, Belgium), D. Vieluf (Hamburg, Germany), G. Von Pilgrim (Mainz, Germany), S. Wille, A. Warner (Helsingborg, Sweden), E. Young (Amersham, U.K.), and the UCB ETAC team.

Dr. D. Chellun and B. Winters (UCB, Brussels, Belgium) provided support for the statistical analysis of the results in this paper.

\section{REFERENCES}

1. Hindmarch I 1995 Psychometric aspects of antihistamines. Allergy 50:48-54

2. Spencer CM, Faulds D, Peters DH 1993 Cetirizine - a reappraisal of its pharmacological properties and therapeutic use in selected allergic disorders. Drugs 46:10551080

3. Volkerts ER, Vanlaar M 1995 Specific review of the psychometric effects of cetirizine. Allergy 50:55-60

4. Ramekers JG, Vermeeren A 2000 All antihistamines cross blood-brain barrier. BMJ 321:572

5. Passani MB, Bacciottini L, Mannaioni PF, Blandina P 2000 Central histaminergic system and cognition. Neurosci Biobehav Rev 24:107-113

6. Vuurman EFPM, Van Veggel LMA, Uiterwijk MMC, Leutner D, O’Hanlon JF 1993 Seasonal allergic rhinitis and antihistamine effects on children's learning. Ann Allergy $71: 121-126$

7. Vuurman EFPM, VanVeggel LMA, Sanders RL, Muntjewerff ND, O’Hanlon JF 1996 Effects of Semprex-D and diphenhydramine on learning in young adults with seasonal allergic rhinitis. Ann Allergy 76:247-252

8. Warner JO on behalf of the ETAC ${ }^{\text {TM }}$ Study Group 1998 Allergic factors associated with the development of asthma and the influence of the citirizine in a double blind, randomised, placebo control trial: first results of ETAC. Pediatr Allergy Immunol 9:116-124

9. Simons FER on behalf of the ETAC'M Study Group 1999 Prospective, long term safety evaluation of the $\mathrm{H}_{1}$ receptor antagonist citirizine in very young children with atopic dermatitis. J Allergy Clinl Immunol 104:433-440

10. Richman N, Graham PJ 1971 A behaviour screening questionnaire for use with three year old children: preliminary findings. J Child Psychol Psychiatry 12:5-33

11. Hogg C, Rutter M, Richman N 1997 Emotional and behavioural problems in children. In: Sclare I (ed) Child Psychology Portfolio. NFER-Nelson, Windsor, Berkshire, U.K., pp 35-45

12. Richman N, Stevenson J, Graham PJ 1982 Pre-school to School. A Behavioural Study. Academic Press, London

13. McCarthy D 1972 McCarthy's Scales of Children's Ability. Psychological Corporation, New York

14. McCarthy D 1976 Manuel des Echelles d'aptitudes pour enfants de McCarthy M.S.C.A. Les Editions du Centre de Psychologie Applique, Paris
15. van der Meulen BF, Smrkovsky M, 1985 McCarthy OntwikkelingsschalenHandleiding. Swets Zeitlinger B.V., Lisse, The Netherlands

16. Jacobson SW, Chiodo LM, Jacobson JL 1999 Breastfeeding effects on the intelligence quotient in 4- and 11-year-old children. Pediatrics 103:E711-E716

17. Aylward GP, Verhulst SJ 2000 Predictive utility of the Bayley Infant Neurodevelopmental Screener (BINS) risk status classifications: clinical interpretation and application. Dev Med Child Neurol 42:25-31

18. Waisbren SF, Haley W, Levy HL, Shifrin H, Allred E, Azen C, Chang P-N, Cipcic-Schmidt S, de al Cruz F, Hall R, Matalon R, Nanson J, Rouse B, Trefz F, Koch R 2000 Outcome at age 4 years in offspring of women with maternal phenylketonuria: the Maternal PKU Collaborative Study. JAMA 283:756-762

19. Cohen J 1988 Statistical Power Analysis for the Behavioural Sciences. Lawrence Erlbaum, Hillsdale, NJ, U.S.A.

20. Jacobson NS, Truax P 1991 Clinical significance: a statistical approach to defining meaningful change in psychotherapy research. J Consult Clin Psychol 59:12-19

21. Reynolds JEF 1999 Martindale, the Complete Drug Reference, 32nd Ed. Pharmaceutical Press Royal Pharmaceutical Society of Great Britain, London, p 397

22. Kotes H 1999 Commnetary: self-management programs in the treatment of asthma. J Ped Psychol 24:331-332

23. Schobinger R, Florin I, Reichbauer M, Lindemann H, Zimmer C 1993 Childhood asthma: mothers' affective attitude, mother-child interaction and children's compliance with medical requirements. J Psychosom Res 37:697-707

24. Seifer R, Sameroff AJ, Baldwin CP, Baldwin A 1992 Child and family factors that ameliorate risk between 4 years and 13 years of age. J Am Acad Child Adol Psychiatry 31:893-903

25. Scolnik D, Nulman I, Rovet J, Gladstone D, Czuchta D, Gardner HA, Gladstone R, Ashby P, Weksberg R, Einarson T, Koren G 1994 Neurodevelopment of children exposed in utero to phenytoin and carbamazepine monotherapy. JAMA 271:767-770

26. Bellinger D, Sloman J, Leviton A, Rabinowitz M, Needleman HL, Waternaux C 1991 Low-level lead exposure and children's cognitive function in the preschool years. Pediatrics 87:219-227

27. McMichael AJ, Baghurst PA, Wigg NR, Vimpani GV, Robertson EF, Roberts RJ 1988 Port Pirie cohort study: environmental exposure to lead and children's abilities at the age of four years. N Engl J Med 319:468-475

28. Huel G, Tubert P, Frery N, Moreau T, Dreyfus J 1992 Joint effect of gestational age and maternal lead exposure on psychomotor development of the child at six years. Neurotoxicology 13:249-254

29. Lewis M, Worobey J, Ramsay DS, McCormack MK 1992 Prenatal exposure to heavy-metals: effect on childhood cognitive skills and health status. Pediatrics 89:1010-1015

30. Campbell SB 1995 Behavior problems in preschool children: a review of recent research. J Child Psychol Psychiatry 36:113-149

31. Pal DK, Das T, Chaudhury G, Johnson AL, Neville BGR 1998 Randomised controlled trial to assess acceptability of phenobarbital for childhood epilepsy in rural India. Lancet 351:19-23

32. Steinhausen H-C, Willms J, Spohr HL 1994 Correlates of psychopathology and intelligence in children with fetal alcohol syndrome. J Child Psychol Psychiatry 35:323-331

33. Grant JA 2000 Molecular pharmacology of second-generation antihistamines. Allergy Asthma Proc 21:135-140

34. Simons FER, Fraser TG, Reggin JD, Simons KJ 1996 Comparison of the central nervous system effects produced by six H1-receptor antagonists. Clin Exp Allergy 26:1092-1097 